\title{
Short-Period Disturbances in the Ionosphere Observed at the Time of Typhoons in September 1982 by a Network of HF Doppler Receivers*
}

\author{
Takashi OKuZawA ${ }^{1}$, Takashi Shibata ${ }^{1}$, Takumi ICHINOSE ${ }^{2}$, Kazuyoshi TAKAGI ${ }^{2}$, Chikao

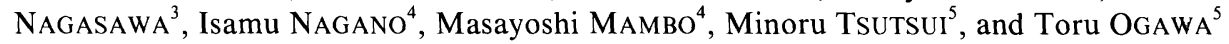 \\ ${ }^{1}$ Department of Applied Electronic Engineering, University of Electro-Communications, \\ Chofu-shi, Tokyo, Japan \\ ${ }^{2}$ Department of Electronics, Doshisha University, Kyoto, Japan \\ ${ }^{3}$ Department of Electrical Engineering, Tokyo Metropolitan University, Tokyo, Japan \\ ${ }^{4}$ Department of Electrical Engineering, Kanazawa University, Kanazawa, Japan \\ ${ }^{5}$ Radio Atmospheric Science Center, Kyoto University, Uji, Japan
}

(Received June 5, 1985; Revised December 10, 1985)

Short-period disturbances of the ionosphere were observed by a network of HF Doppler receivers in central Japan at the time of typhoons 18 and 19 which crossed the Islands of Japan successively in September 1982.

Both dynamic and static spectral analyses on sample records revealed that (1) these waves have the periods ranging between 1.4 and 9.7 min that correspond to infrasound at F-layer heights (and partly to gravity wave at E-layer heights), (2) the spectral content varies from hour to hour, from station to station for a given typhoon, and further one typhoon to the other, and (3) the spectral fine structure does not accord with existing theoretical prediction for thunderstorms. It is, therefore, plausible that the observed spectral peaks arose from the characteristics of the radiation sources in the typhoon air mass.

Horizontal and vertical phase velocities, and corresponding wavelengths of the ionospheric waves were also measured using cross-correlation method. It is shown that (1) the horizontal phase velocities take similar values to those observed during the severe thunderstorms and tornadoes so far reported, with scatter range of the values being slightly larger than the latter two, and (2) the mean values of the upward vertical phase velocities are several to ten times larger than those of the horizontal ones.

\section{Introduction}

The ionosphere is capable of sustaining a large number of wave phenomena, as is well illustrated with BOOKER's (1979) composite spectrum (Fig. 7 of his paper). Acoustic gravity waves (AGW) occupy the spatial frequency (wavenumber) band from $10^{-4} \mathrm{~km}^{-1}$ (the inverse of the diameter of the earth) up to several $10^{-1} \mathrm{~km}^{-1}$. While they become tidal waves at the low-frequency (temporal) end, they are separated by a

*Partly presented at International MAP Symposium in Kyoto 1984. 
narrow stopband from infrasonic waves at the high-frequency end.

The significant role of $\mathrm{AGW}$ in the ionospheric dynamics, e.g., in the maintenance of mean thermospheric temperature on a global scale (ROBLE and DICKINSON, 1973; KLOSTERMEYER, 1973), and the generation of spread-F and ionospheric scintillation (KELLY et al., 1981; RÖTTGER, 1981), have been extensively studied during the past two decades. However, the correlation between the AGW at the ionospheric heights and the natural perturbation sources (weather storms, volcanic eruption, supersonic auroral arc motion and earthquake etc.) and man-made sources (supersonic aircraft and nuclear explosion etc.) has not satisfactorily been clarified yet from the experimental basis, and therefore it should be carefully investigated one by one.

It is well known that the gravity waves are relatively free from absorption, whereas acoustic waves are subject to substantial absorption in the atmosphere mainly by viscosity, although amplification in the relative amplitude of the wave with the rate of $\exp (-z / 2 H)$, where $H$ is the locally defined scale height, comes into play so as to compensate the absorption to some extent. This may be reason why we have hardly detected the acoustic waves at ionospheric heights. Exception are the HF Doppler soundings of the F-layer reported by GEORGES (1967, 1968, 1973). BAKER and DAVIES (1969), DAVIES and JONES (1971a, 1972, 1973), PRASAD et al. (1975), SMITH and HUNG (1975) and RAJU et al. (1981). They have shown that infrasonic waves with the periods of the order of one minute originated from thunderstorms and tornadoes, and contributed significantly to ionospheric perturbations. Their observations were related to severe storms that occurred in the central area of the continental USA, the Florida Peninsula and the eastern part of the Peninsular India in the Bay of Bengal. In this connection, PRASAD et al.'s (1975) suggestion should be noteworthy that there may be not only difference between storm types but also geographical dependency in the manifestation of atmospheric infrasound at ionospheric heights. The ionospheric disturbances associated with cyclonic severe storms have also been detected by the HF Doppler method. As is widely known, 'typhoon' is such a kind of severe storm that is born usually off the Philippines. It occasionally travels northward along the western border of the Pacific Ocean and sometimes attacks the mainland of Japan. TSUTSUI and OGAWA (1973) gave a brief description of the ionospheric effect of typhoon 20 of 16-17 September 1972, while HUNG and Kuo (1978) argued the correlation between the observed HF Doppler shift variations and the activity of hurricane Eloise on 22-23 September 1975. HUANG et al. (1985) recently reported that their Doppler frequency sounding array of direct vision type was set up in Taiwan and used successfully to detect the AGW generated by typhoon, although the detectability was not very high, for instance, 2 out of 12 for their studies. All of these authors focussed their attention to the ionospheric disturbances with the waves period of the order of ten minutes, i.e., the gravity wave range at the $F$-region heights. This implies that at present there are few published papers on the ionospheric infrasound generated by typhoons.

Several atmospheric waves were observed by a network of HF Doppler receivers in central Japan at the time of two typhoons, 18 and 19, which attacked successively 
the Islands of Japan in September 1982 during MAP period. The purpose of this paper is to present experimental evidence of the ionospheric waves with the wave period of the order of one minute associated with the typhoons, mainly with respect to the variation of autospectra and the wave parameters defined as to the traveling ionospheric disturbances (TID).

The present observations have two advantages; i.e., (1) data from multi-station observations of 5 and $8 \mathrm{MHz}$ waves transmitted by JJY station are available with the aid of a network of the HF Doppler receivers in central Japan, and (2) comparison of the results with several respects not only between the two typhoons but also among the separated stations can be done.

In this paper, we firstly make dynamic and static power spectral analyses to observe temporal and spatial variations of spectral content.

Simultaneous transmissions from a common JJY station on the ground via F-layer reflection to three selected different locations give a horizontal triangle in the ionosphere. As a TID passes through the three apexes of the triangle, disturbing each in succession, the time lags are measured by the cross-spectrum analyses. From the time lags thus obtained and the known spacings, we will secondly calculate the horizontal phase velocity and direction of each Fourier component across the triangle. The apparent vertical phase velocity will be also measured using different two frequencies if the difference in reflection heights between them is appreciable.

The results are then briefly discussed from the viewpoint of troposphereionosphere coupling.

\section{Observations}

The method of observation and the simple theory involved are described by DAVIES (1969) and DAVIES and JONES (1971b). The present system of Doppler sounder array consists of nine receiving stations of JJY signals from transmitters located at Nazaki $\left(36.18^{\circ} \mathrm{N}, 139.85^{\circ} \mathrm{E}\right)$, Ibaraki, Japan, in operation at several HF frequencies (see Fig. 1). The geographical locations, great circle distances from Nazaki and surface locations of midpoint of the radio circuit, of the receiving stations with sounding radio frequencies (available for the present analyses) are shown in Table 1.

The principal data of the two typhoons, 18 and 19, are summarized in Table 2: Japan Meteorological Agency declared these typhoons to be "the biggest two" among the September 1982 storms. Travel courses of the typhoons are shown in Fig. 2 by thick lines. In the figure numerals being attached to each curve on the right side denote day numbers, and those on the opposite side represent central pressure values (in $\mathrm{hPa}$ ). Small empty circles on the curves indicate the positions at $9 \mathrm{~h}$ $\mathrm{JST}\left(135^{\circ} \mathrm{EST}=\mathrm{UT}+9 \mathrm{~h}\right)$, and successive knots indicate the positions at intervals of six hours. The typhoon 18 landed at Omaezaki, Sizuoka, at $18 \mathrm{~h} 12 \mathrm{~d}$ JST. Running through the northern part of the Honshu Island, it decayed down to an extratropical cyclone (with central pressure, $986 \mathrm{hPa})$ at $\left(41.6^{\circ} \mathrm{N}, 141.6^{\circ} \mathrm{E}\right)$ on the Sea of Japan at $08 \mathrm{~h} 13 \mathrm{~d}$ JST. The typhoon 19 struck Ashizuri point, Ehime, around $02 \mathrm{~h} 30 \mathrm{~min} 25 \mathrm{~d}$ 


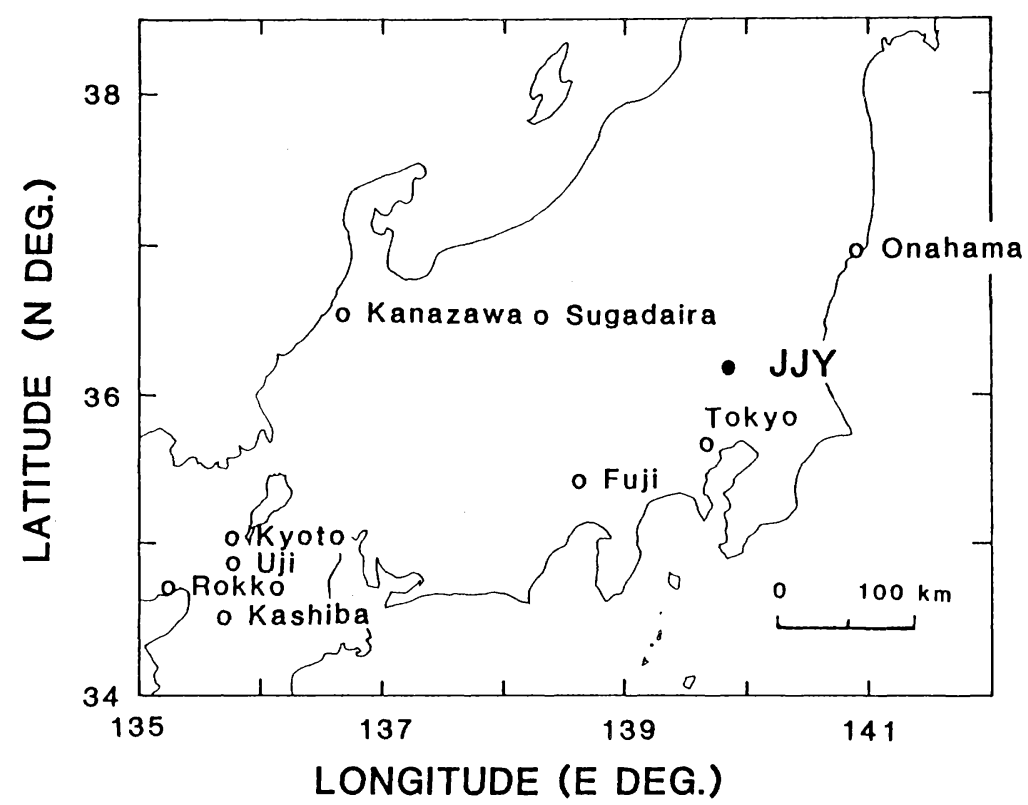

Fig. 1. A network of the HF Doppler receivers with a common JJY transmitter at Nazaki.

Table 1. Summary of the HF Doppler array used in this study.

\begin{tabular}{|c|c|c|c|c|c|c|c|}
\hline \multicolumn{2}{|c|}{$\begin{array}{c}\text { Station } \\
\text { (Abbreviation) }\end{array}$} & \multicolumn{2}{|c|}{$\begin{array}{l}\text { Geographic } \\
\text { coordinates } \\
\left({ }^{\circ} \mathrm{N},{ }^{\circ} \mathrm{E}\right)\end{array}$} & \multirow{2}{*}{$\begin{array}{c}\begin{array}{c}\text { Distance } \\
\text { from Nazaki } \\
(\mathrm{km})\end{array} \\
128.0\end{array}$} & \multicolumn{2}{|c|}{$\begin{array}{l}\text { Geographic coordinates } \\
\text { of the mid-path point } \\
\left({ }^{\circ} \mathrm{N},{ }^{\circ} \mathrm{E}\right)\end{array}$} & \multirow{2}{*}{$\frac{\begin{array}{c}\text { Remarks } \\
(\mathrm{MHz})\end{array}}{8}$} \\
\hline Onahama & (ONA) & 36.94 & 140.93 & & 36.56 & , 140.39 & \\
\hline Kanazawa & $(\mathrm{KAN})$ & 36.58 & , 136.62 & 292.5 & 36.39 & , 138.24 & 8,5 \\
\hline Sugadaira & (SUG) & 36.52 & , 138.32 & 142.0 & 36.35 & , 139.09 & 8 \\
\hline Tokyo & (TOK) & 35.67 & , 139.67 & 59.3 & 35.93 & , 139.76 & 8,5 \\
\hline Fuji & $(\mathrm{FUJ})$ & 35.42 &,$\quad 138.62$ & 139.7 & 35.80 & , 139.23 & 8 \\
\hline Kyoto & (KYO) & 35.03 &,$\quad 135.77$ & 390.5 & 35.62 &,$\quad 137.80$ & 8,5 \\
\hline Uji & (UJI) & 34.89 & , 135.78 & 395.3 & 35.55 & , 137.80 & 8,5 \\
\hline Rokko & (ROK) & 34.72 & , 135.23 & 448.9 & 35.47 & , 137.52 & 8,5 \\
\hline Kashiba & (KAS) & 34.53 & , 135.67 & 421.2 & 35.37 & , 137.74 & 8,5 \\
\hline Nazaki & (JJY) & 36.18 & , 139.85 & - & - & - & $\begin{array}{l}\text { Transmitting } \\
\text { station }\end{array}$ \\
\hline
\end{tabular}

JST. It ran through the district of western Chugoku with decay in its energy, and became an extratropical cyclone (with central pressure, $992 \mathrm{hPa}$ ) at $\left(37.0^{\circ} \mathrm{N}, 132.5^{\circ} \mathrm{E}\right.$ ) on the Sea of Japan at $15 \mathrm{~h} 25 \mathrm{~d}$ JST. After traversing the Hokkaido Island, it passed 
Table 2. Principal data of typhoons 18 and 19 in September 1982.

\begin{tabular}{|c|c|c|c|c|c|c|}
\hline \multirow[b]{2}{*}{$\begin{array}{l}\text { Typhoon } \\
\text { Name }\end{array}$} & \multicolumn{2}{|c|}{ Typhoon period } & \multicolumn{3}{|c|}{ Minimum central pressure } & \multirow[b]{2}{*}{$\begin{array}{c}\text { Maximum } \\
\text { wind speed } \\
\left(\mathrm{ms}^{-1}\right)\end{array}$} \\
\hline & $\begin{array}{c}\text { Beginning } \\
\text { (mon, day, hr) }\end{array}$ & $\begin{array}{l}\text { Ending } \\
\text { (day, hr) }\end{array}$ & $\begin{array}{c}\text { Time } \\
\text { (mon, day, hr) }\end{array}$ & $\begin{array}{l}\text { Location } \\
\left({ }^{\circ} \mathrm{N},{ }^{\circ} \mathrm{E}\right)\end{array}$ & $\begin{array}{c}\text { Central } \\
\text { pressure } \\
(\mathrm{hPa})\end{array}$ & \\
\hline 18 & Sept., 6,9 & 13,8 & Sept., 9,9 & $21.5,134.6$ & 955 & 40 \\
\hline 19 & Sept., 16,21 & 25,15 & Sept., 18,15 & $19.9,127.5$ & 940 & 45 \\
\hline
\end{tabular}

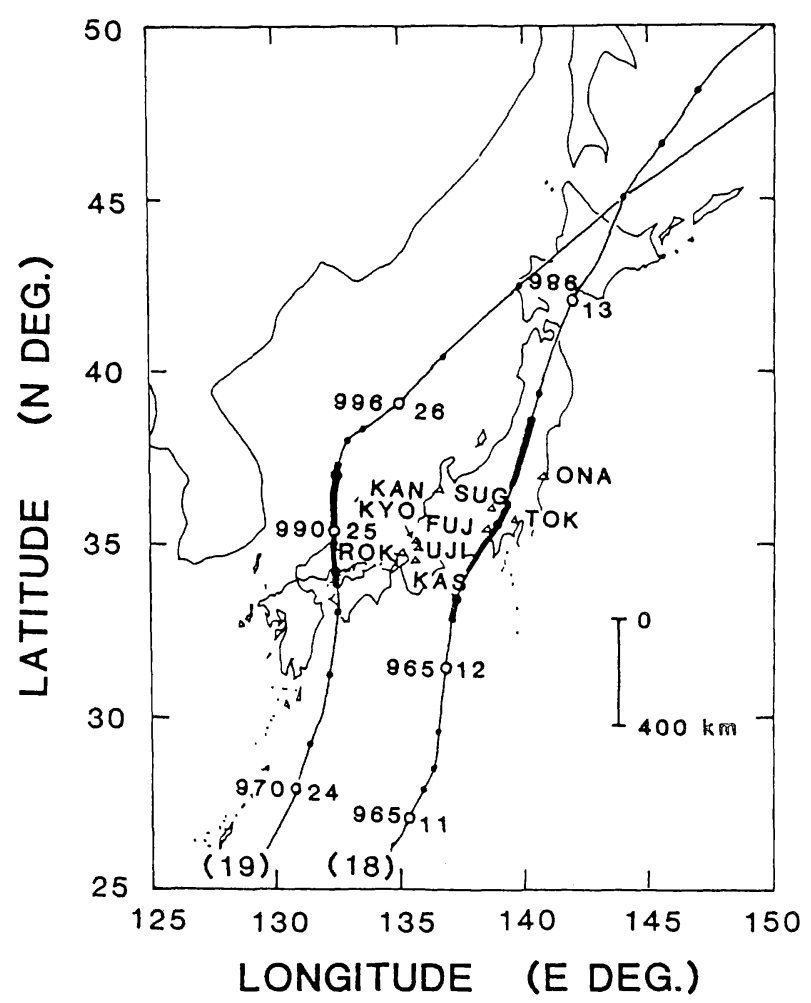

Fig. 2. Travel courses of typhoons 18 and 19 in September 1982 and the location of HF Doppler stations.

out into the Sea of Okhotsk.

Figures 3(a) and 3(b) exhibit sample records of the HF Doppler frequency shift variations observed in the daytime at Uji, Kashiba, Rokko and Kyoto (called hereafter "Kansai subarray") on 12 September, and at Onahama, Sugadaira, Fuji and Tokyo (called hereafter "Kanto subarray") on 25 September 1982, respectively, when fluctuation activity was highest at the time of typhoons 18 and 19, respectively. The 
12 September 1982
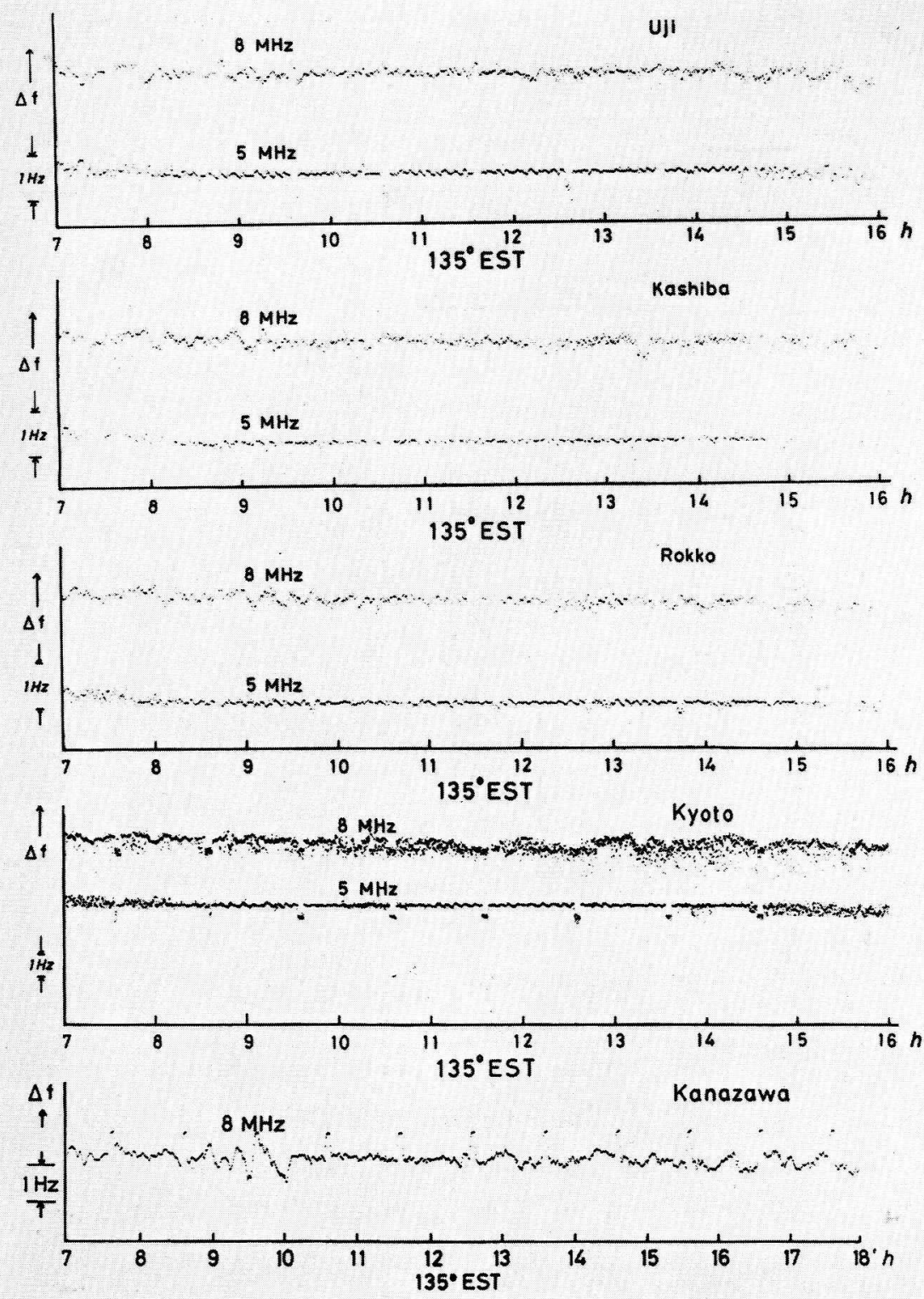

(a)

Fig. 3. (a) Sample records of the Doppler variations of JJY waves associated with typhoon 18. (b) Sample records of the Doppler variations of JJY waves associated with typhoon 19. (c) Doppler records expanded from those inside the three frames in Fig. 3(b). 

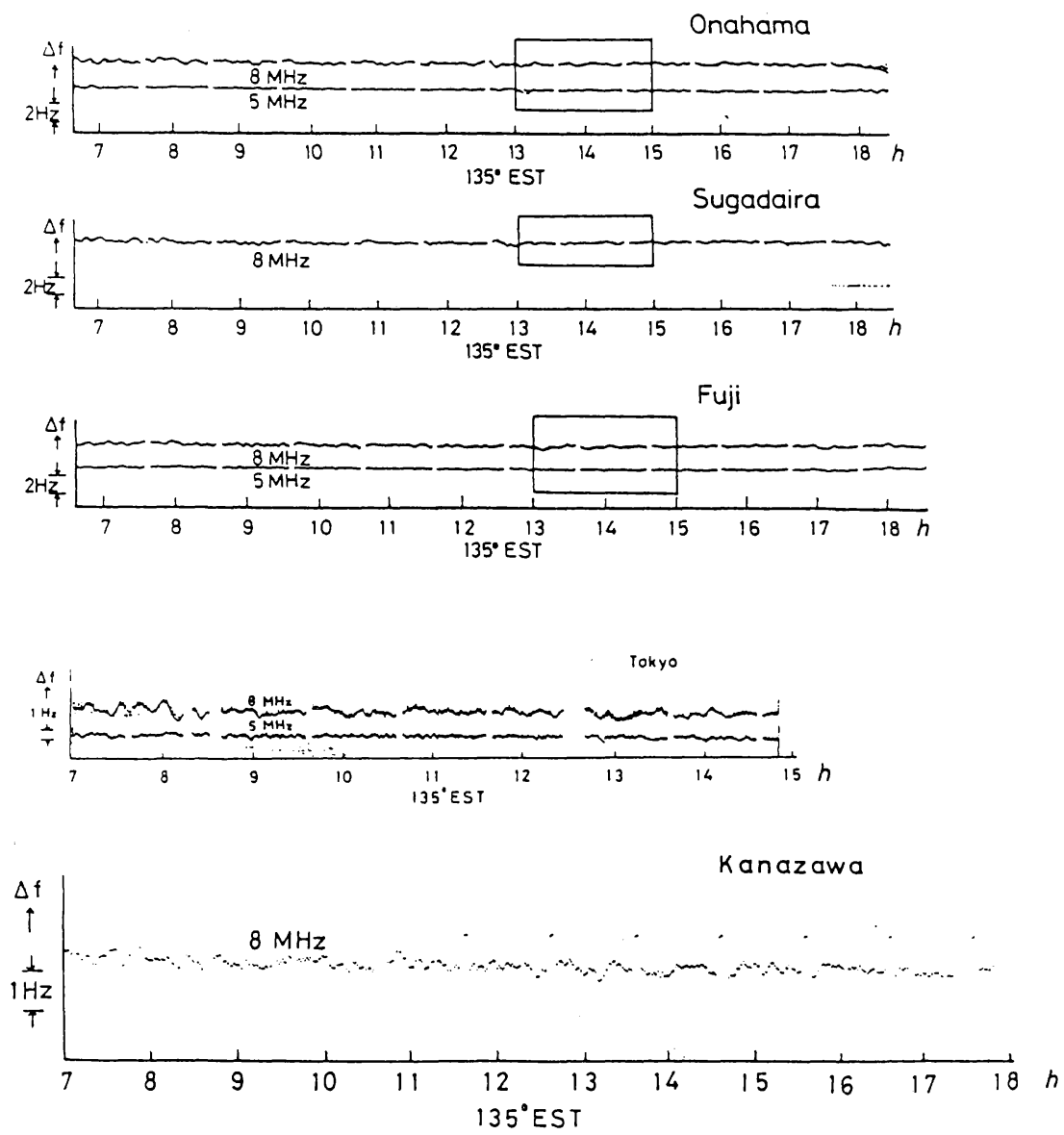

(b)

Fig. 3 (continued).

data samples from Kanazawa are also presented in both of the figures (a) and (b) for the purpose of seeing into the ionospheric effects by separate typhoons at a single station. For the sake of visual inspection, Figure 3(c) shows the expanded Doppler traces taken from three frame parts in Fig. 3(b). It is evident, especially from the records of $5 \mathrm{MHz}$ signals of (a) and $8 \mathrm{MHz}$ signals of (b), that small-amplitude, quasi sinusoidal oscillations with the wave periods of a few to ten minutes and Doppler shifts of the order of $0.1 \mathrm{~Hz}$ in amplitude dominate the Doppler traces. In the case of 


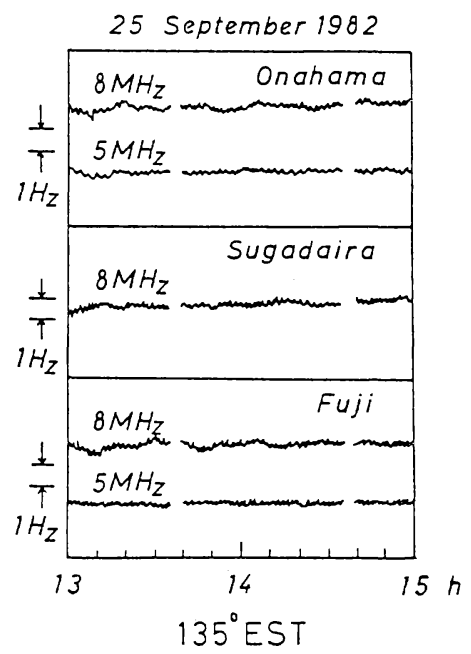

(c)

Fig. 3 (continued).

typhoon 18, these short-period oscillations have been observed consecutively during the night hours of 12 September and also several hours after $0 \mathrm{~h}$ of 13 September 1982. These oscillations have been observed when the typhoon center was inside the circle with a radius of about $450 \mathrm{~km}$ centered at the mid-path point between the JJY $(5 \mathrm{MHz}$ wave) station and the stations of the Kansai subarray (corresponding typhoon positions are indicated by the broad thick line of travel courses in Fig. 2). The Doppler records from the other stations were not useful to determine the beginning and ending times of the oscillations because of the effects of fade-out $(8 \mathrm{MHz})$ and interference $(5$ $\mathrm{MHz}$ ) of the JJY waves during nighttime period. It should be noticed that the background oscillations with the period of the order of ten minutes have been superimposed on the Doppler traces, having peak-to-peak amplitude values up to 1 $\mathrm{Hz}$ or less, during these typhoon periods as for the case of usual days. Before pursuing numerical analyses on the Doppler records, the data gaps which arise from the scheduled interruption of the JJY transmission from 35 to 39 min every hour were interpolated by the method of AKIMA (1970).

\section{Data Analyses}

\subsection{Spectral characteristics}

In order to find a clue to clarify the coupling between typhoon and ionosphere, we made dynamic power spectral analyses and static spectral analyses. In these analyses the maximum entropy method (MEM) (BURG, 1975) was used to obtain 
high-resolution power spectra of the HF Doppler records from the observation array. The Doppler data are in digital form with sampling intervals of $10 \mathrm{~s}$ (partly $30 \mathrm{~s}$ ) so that the corresponding Nyquist frequency is $0.05 \mathrm{~Hz}(0.017 \mathrm{~Hz})$. The MEM has the shortcoming about which consensus has not yet been reached on how to choose the optimum number of the prediction error filter (called hereafter $M$ ). Based on our experience (OKUZAWA and DAVIES, 1981), however, spectra used subsequently in this subsection are the arithmetic mean of three values determined with $M=15,20$ and $25 \%$ of data length. To obtain reasonable resolution for the spectrum analysis, a data window covering $30 \mathrm{~min}$ was selected. This allows a reliable estimation of periodicities with periods up to $10 \mathrm{~min}$ (or $1.6 \times 10^{-3} \mathrm{~Hz}$ ) (COUTILlOT et al., 1977). In the case of dynamic spectra the data window has been shifted by every 5 min increment in the whole data set.

Several typical examples of static spectra from different stations are presented in Fig. 4; (a) for the $5 \mathrm{MHz}$ wave data from Uji, Rokko and Kashiba at the time of typhoon 18, and (b) for the $8 \mathrm{MHz}$ wave data from Onahama, Sugadaira and Fuji at the time of typhoon 19. The local time at the middle of the window is indicated in each panel. It is seen from the figures that (1) there are several spectral peaks with maximum number being 6 in the specified period range of 1 to 10 min for each station, (2) there are spectral peaks which are common to the three stations, for example, at $3.8 \mathrm{~min}$ (2100 JST), 2.8 and $4.4 \mathrm{~min}$ (2200 JST), $3.5 \mathrm{~min}$ (2300 JST), $3.0 \mathrm{~min}$ (0100 JST), and $2.8 \mathrm{~min}(0200 \mathrm{JST})$ in the case of (a), and $5.8 \mathrm{~min}$ (1200 JST), 3.8 and 6.7 min (1300 JST) in the case of (b), but (3) the spectral content varies not only from one typhoon to the other but also one panel to the other, viz., there are hour to hour and station to station variabilities. Similar features have been observed among the spectra of other stations, but will not be presented here.

Figure 5 gives typical examples of the dynamic spectra (a) for the $5 \mathrm{MHz}$ wave data from Uji at the time of typhoon 18 and (b) for the $8 \mathrm{MHz}$ wave data from Fuji for typhoon 19. For comparison purpose, the spectra of $8 \mathrm{MHz}$ wave data from Kanazawa for both typhoons 18 and 19 are also exhibited in (c) and (d), respectively; Kanazawa is located nearly at the middle of two subarray networks, Kansai and Kanto, and has provided the Doppler data of high signal-to-noise ratio during both typhoon periods, so that these data will be of benefit to the comparison. In obtaining Fig. 5, we prewhitened the digitized records of HF Doppler by taking the first difference of the original record to suppress the lower frequencies of gravity wave range. A low-pass filter (BEHANNON and NESS, 1966) was also used with each subset data: filter was a 141-point symmetrical numerical filter of the least-square type, with the cutoff frequency set at $0.0125 \mathrm{~Hz}$. Although the observations were continuous throughout the day, the $8 \mathrm{MHz}$ signals could not be received in the nighttime for the reason mentioned before. The present spectral analyses of the data from Fuji and Kanazawa, therefore, cover the daytime data only.

Outstanding features of these dynamic spectra are that (1) one, or a few, sharply defined spectral peaks appear at the wave periods of a few minutes, changing both shape and amplitude within 1 hour or less, (2) high activity of such spectral peaks (in both duration and amplitude) continues throughout the day on 12 and 25 September 

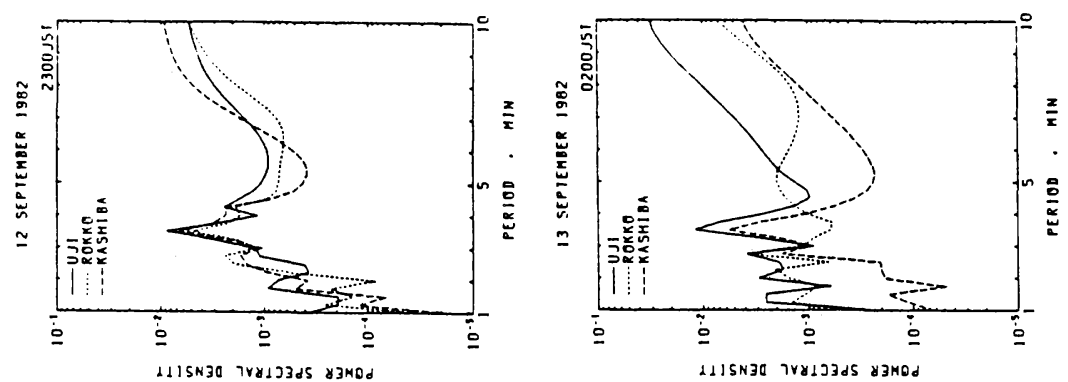

: ถึะ

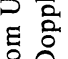

은

สำ 동

.

$\stackrel{4}{4}$

需

퐁.

115N30 TralJ3as 83MD
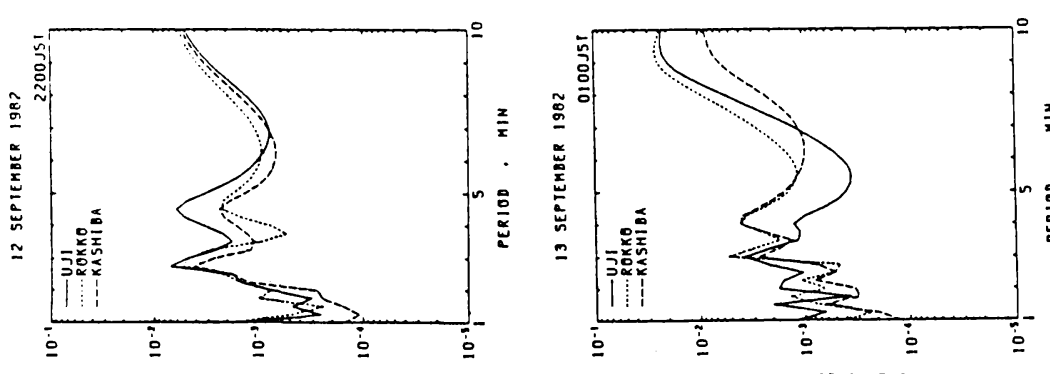

$\sum \pm$

๙

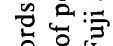

ठํㅓㅇㄷㅗ

ᄂ.

范苟

- คें

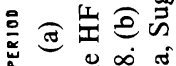

\&

눈 융

혼

11ISN30 רYIJ3dS 83KO

A1ISN30 TrУIJ3dS У3MOd

苋

只

总焉
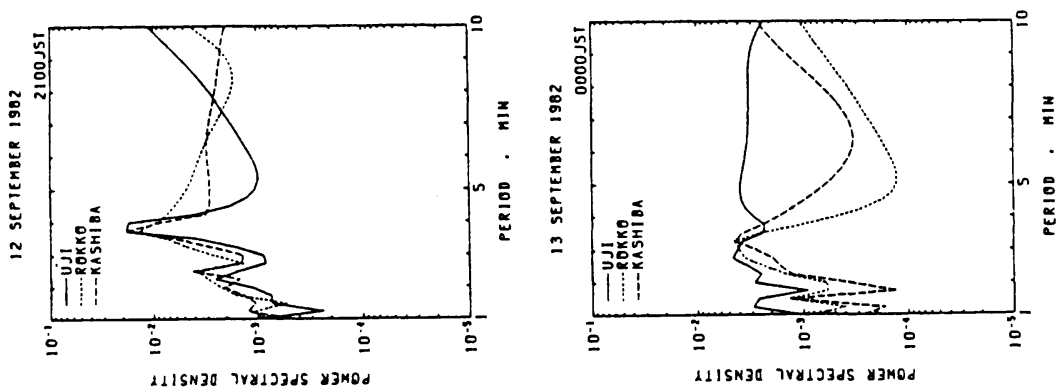

롬에

○

ㄷํㅇำ

牙

을 严

ن 정

(త)

in 

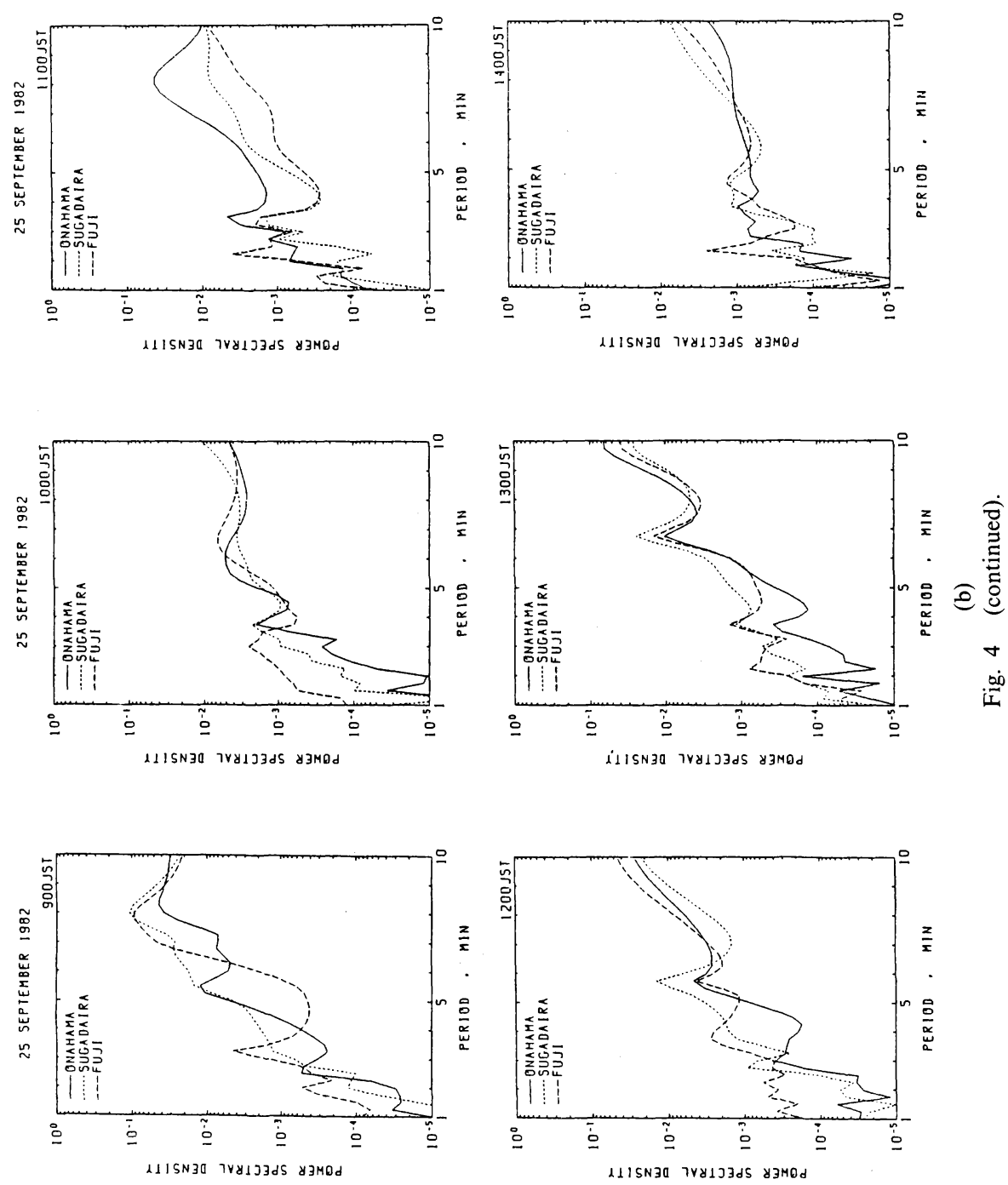

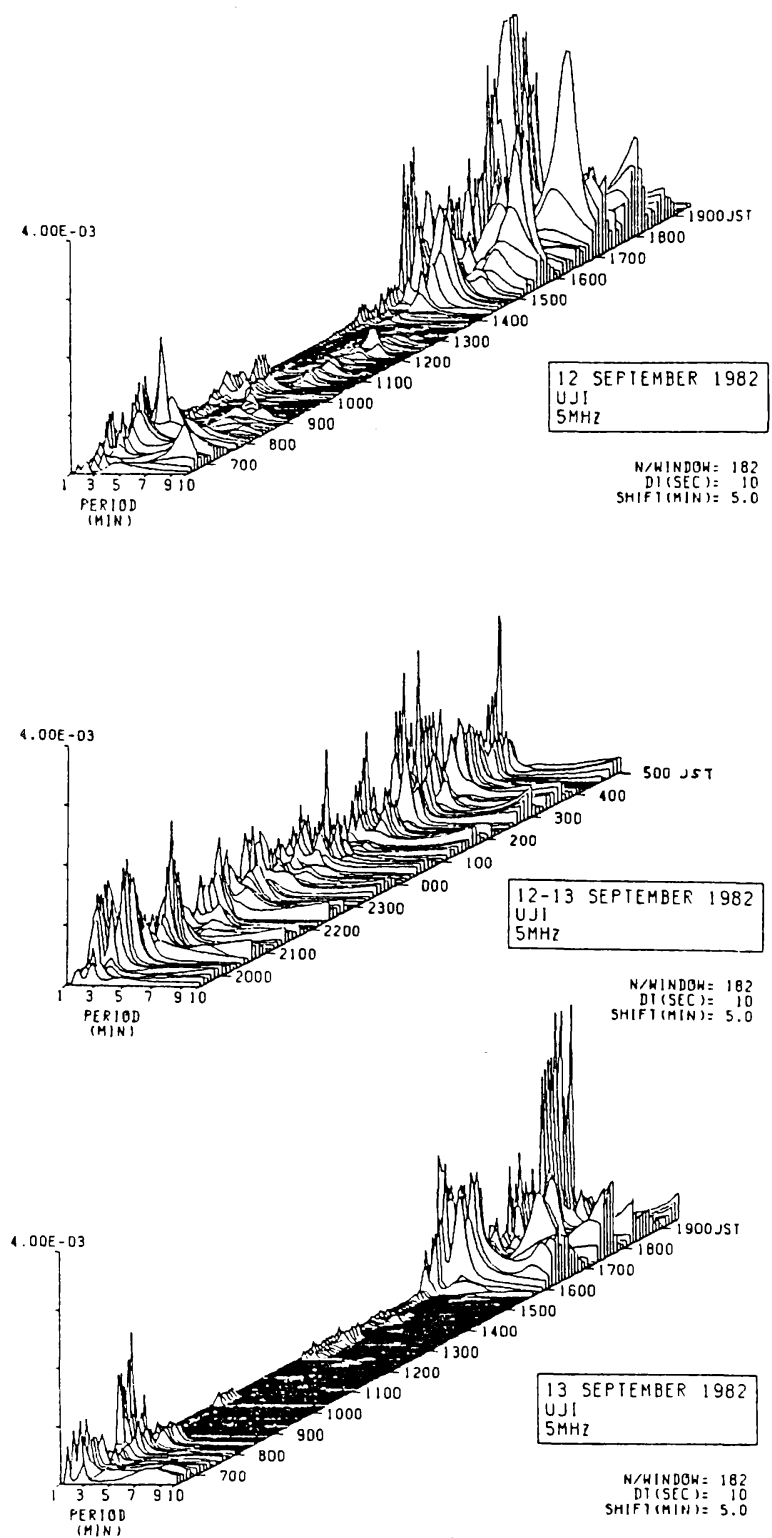

(a)

Fig. 5. (a) Dynamic spectra of the $5 \mathrm{MHz}$ wave data from Uji at the time of typhoon 18. (b) Dynamic spectra of the $8 \mathrm{MHz}$ wave data from Fuji at the time of typhoon 19. (c) Dynamic spectra for the 8 $\mathrm{MHz}$ wave data from Kanazawa for typhoon 18. (d) The same as (c) but for typhoon 19. 

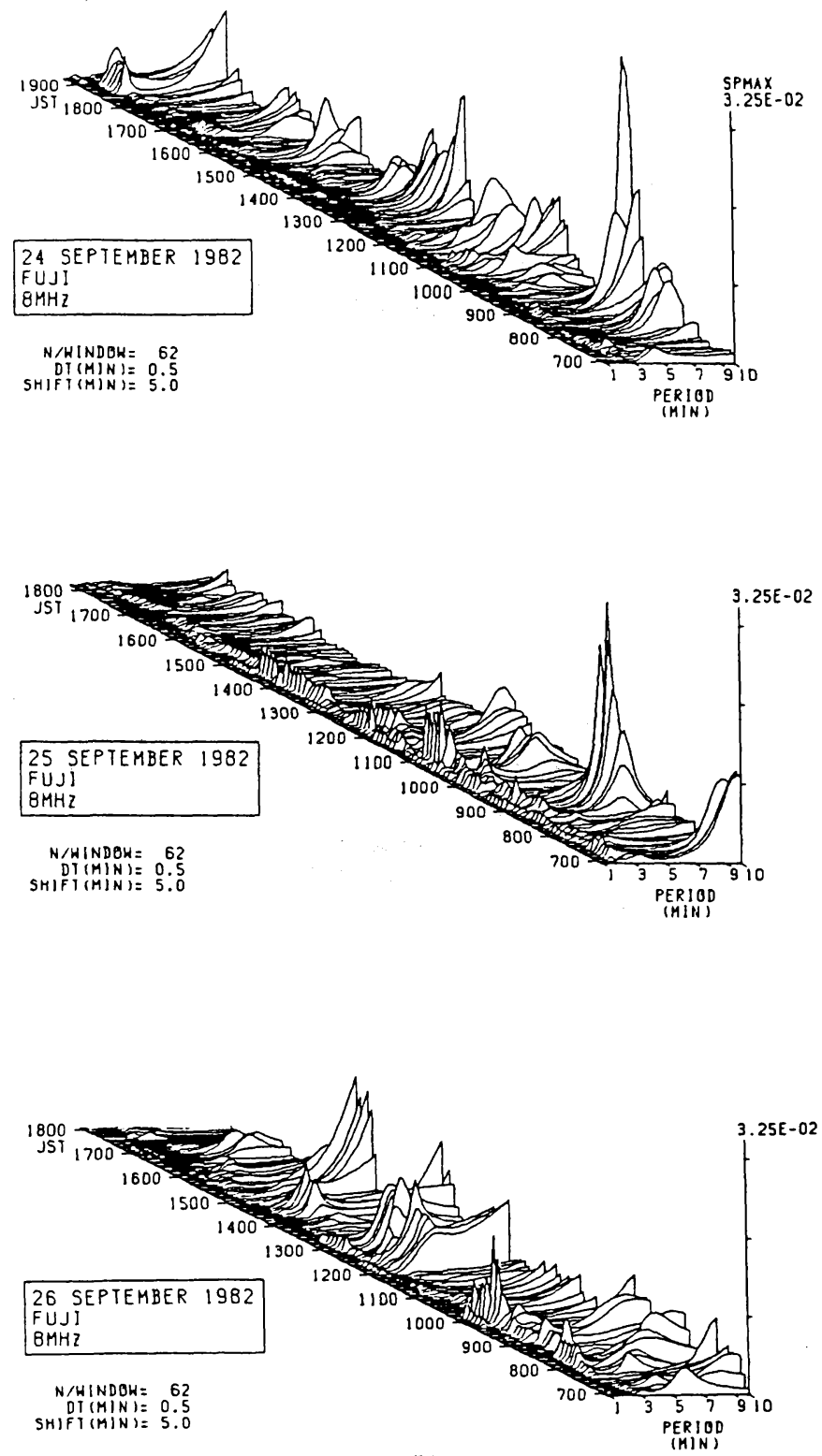

(b)

Fig. 5 (continued).

1982 when the typhoons were running through the Islands of Japan, and a similar trend is seen at the end of the preceding day and the beginning of the next day in both cases for typhoons 18 and 19, and (3) fine structure of the spectra of the Doppler 

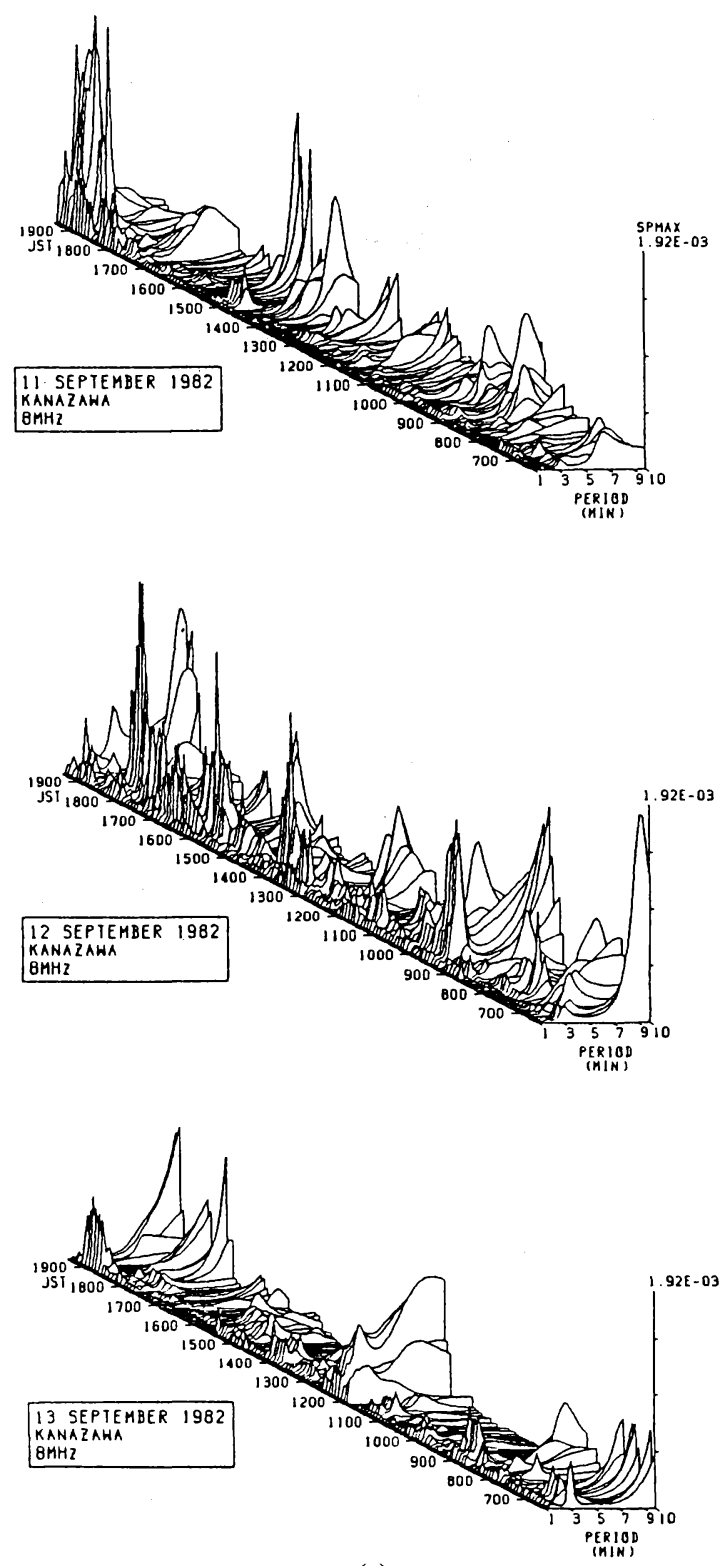

(c)

Fig. 5 (continued).

variations differs not only between the two typhoons but also among the three stations. Anomalously high amplitude of the spectra around the time from 17 to $18 \mathrm{~h}$ should be attributed to the day-to-night transition effects of the ionosphere. 

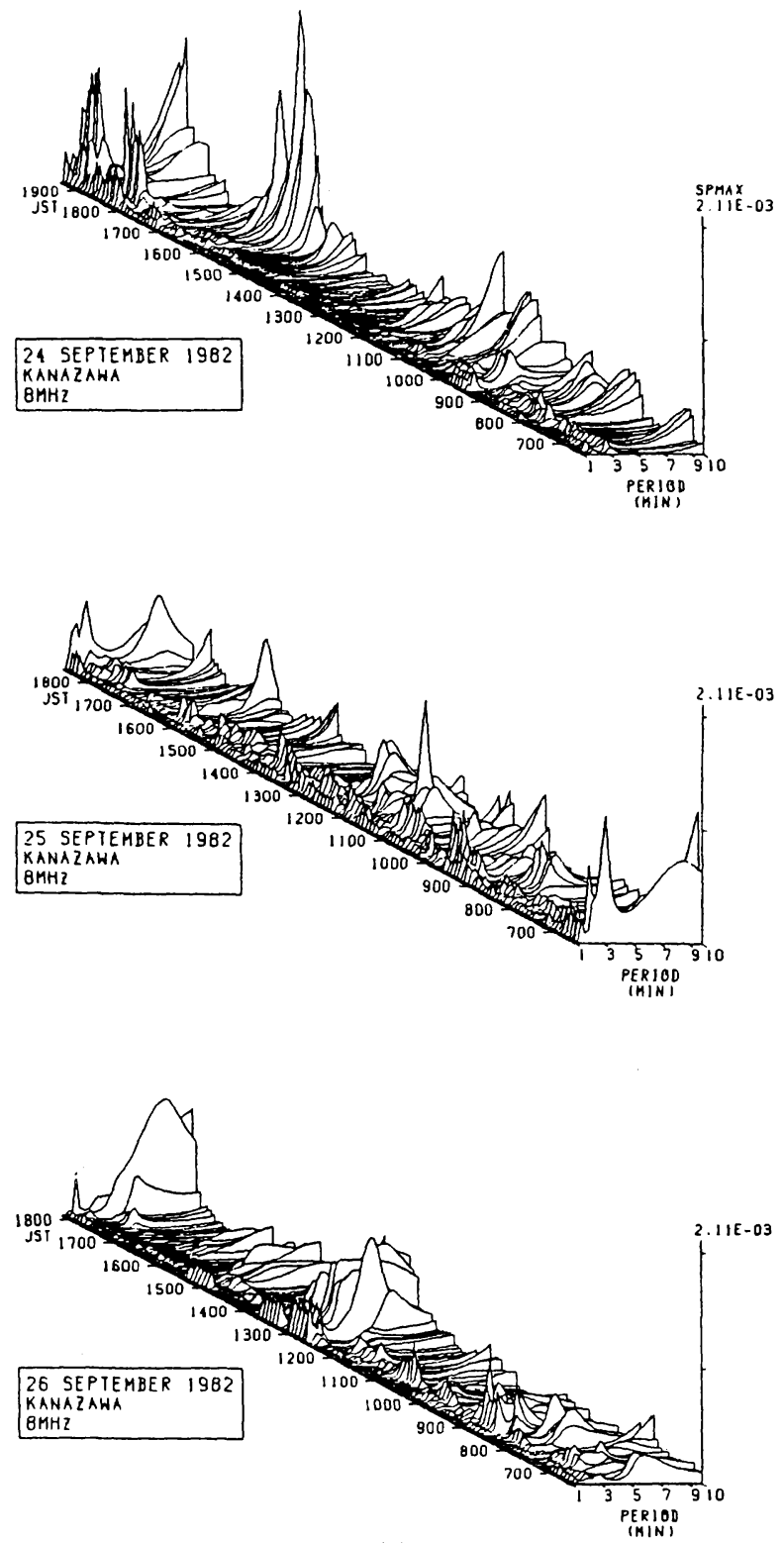

(d)

Fig. 5 (continued).

\subsection{TID features}

Another objective of the analyses is to determine the horizontal and vertical phase velocities of the short-period disturbances which may travel in the ionosphere as TID. 
At least three (two) simultaneous records of the Doppler measurements are needed to survey the horizontal (vertical) velocities. For the present purpose, each trio of the Kansai and Kanto subarrays which forms a triangle of the network receivers was utilized for typhoons 18 and 19, respectively (see Fig. 6). The stations at Kyoto and Tokyo were used in the present analyses as auxiliary points for the subarrays of

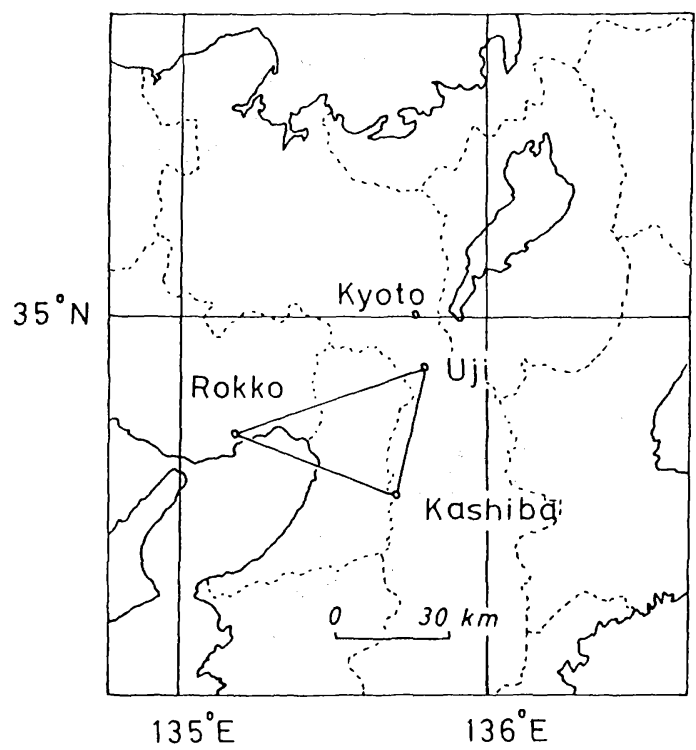

(a)

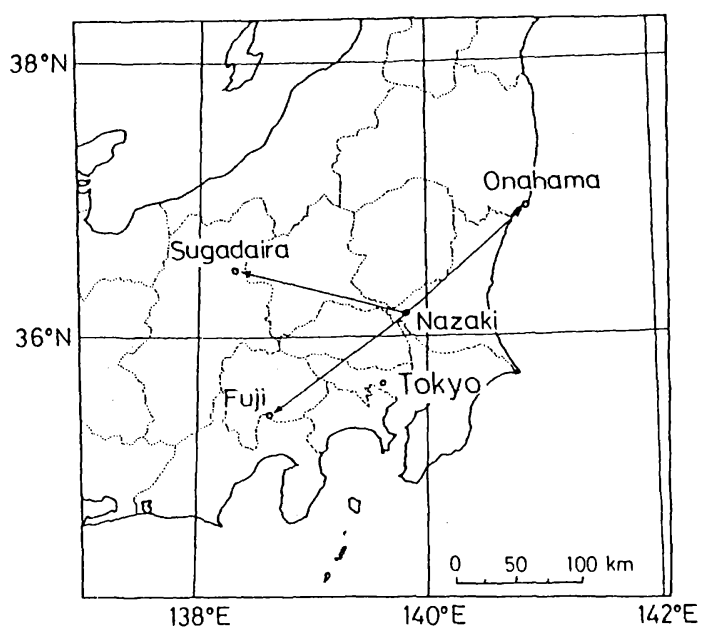

(b)

Fig. 6. Subarray geometry of the HF Doppler frequency sounding system; (a) Kansai, and (b) Kanto. 
Kansai and Kanto, respectively, because sometimes four stations are required when we are to reject those TIDs which do not preserve their coherence as they travel across the measuring system and also when we have a degenerate situation such that the horizontal direction of TID propagation is perpendicular to the line joining any two of the three points. Unfortunately, we could not use the two subarray networks simultaneously, because the latter was operated only during the period of typhoon 19, and continuous records from the former were not available owing to some instrumental trouble at the time of typhoon 19.

Processes of both the prewhitening and the low-pass filtering have not been performed in order to conserve phase information for the present purposes. The cross-spectrum analyses have been made on subset data of the 30 min window for each pair among three (four) stations. The data window has been shifted by every $5 \mathrm{~min}$ in the whole data set. The method of multi-channel MEM (STRAND, 1977; CHEN, 1982) with the M number being 20\% of the data length (AKAIKE and NAKAGAWA, 1972) has been adopted here. Three possible combinations of pairs of stations provide three cross-spectrum densities. The cases of the coherence greater than 0.8 are adopted in the present analyses. From the cross-spectrum densities the time lags are obtained, and then the caes are taken up only if the sum of the time lags among the three stations is smaller than the sampling time so that errors may be reduced in the velocity estimation. The horizontal spacings are taken to be distances between the midpoints of the oblique paths. The determination of phase lag generally involves an ambiguity of integral multiples of $2 \pi$. The lowest-order lag has been chosen throughout the present analyses. The vertical spacings are obtained from true-height analyses of Kokubunji $\left(35.70^{\circ} \mathrm{N}, 139.52^{\circ} \mathrm{E}\right)$ hourly ionograms using the method developed by TITHERIDGE (1967). Details of the method of data analysis have been given by SHIBATA and OKUZAWA (1983).

The azimuthal angle of wave propagation was determined within an accuracy of $8.5^{\circ}$ for the Kansai and $1^{\circ}$ for the Kanto subarray networks, and the horizontal (vertical) phase velocity within $\pm 11 \%( \pm 18 \%)$ for the Kansai and $\pm 0.5 \%( \pm 30 \%)$ for the Kanto subarrays.

Figure 7 shows three typical examples of the calculated results for the data of 12 , 12-13 and 25 September 1982, respectively. From top to bottom in each figure, the spectral peak period, the corresponding horizontal phase velocity, horizontal wavelength and propagation azimuth, are plotted as a function of local time. The individual spectral peak period is the average of three-station autospectra with a simultaneous data window. The spectral peaks are recognized as being common among the three stations if the difference of the peak periods is within $15 \mathrm{~s}$. We had one to six peaks per data window in the period range of 1.4 to $9.7 \mathrm{~min}$. These are distinguished from each other using different symbols in the figures. The $5 \mathrm{MHz}$ wave data from the Kansai subarray and the $8 \mathrm{MHz}$ wave data from the Kanto subarray are used in the analyses because of high data quality. As a reference, the calculated true-reflecting heights are shown in Fig. 8; (a) for Uji-Nazaki (JJY) path, and (b) for Tokyo- Nazaki path, applied to the Kansai and the Kanto subarray, respectively.

Outstanding features deduced from these analyses are summarized as follows; 

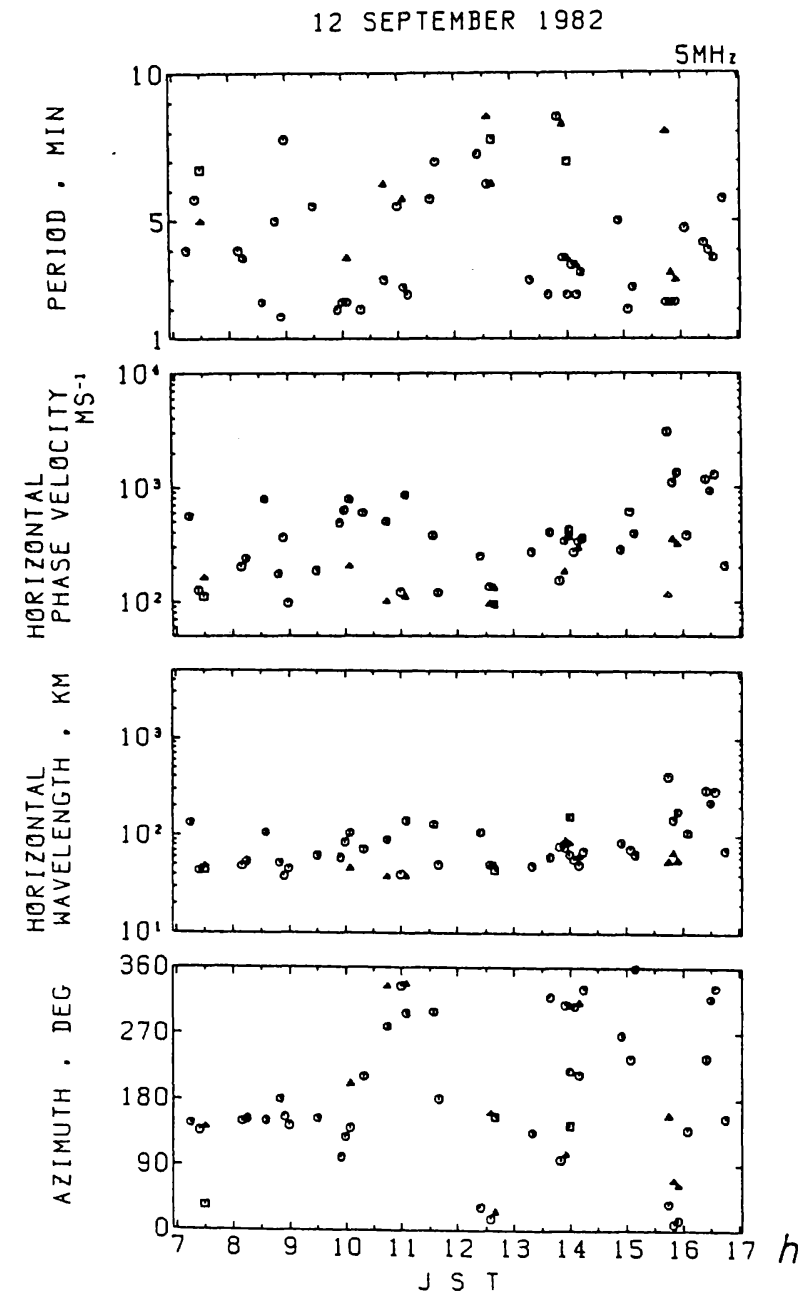

(a)

Fig. 7. (a) TID parameters (in the horizontal direction) vs local time during the daylight hours of 12 September 1982 (typhoon 18). (b) TID parameters (in the horizontal direction) vs local time during the nighttime of 12-13 September 1982 (typhoon 18). (c) TID parameters (in the horizontal direction) vs local time during the daylight hours of 25 September 1982 (typhoon 19).

(1) The daytime (nighttime) horizontal velocities take the values from about $7 \times 10(9 \times 10) \mathrm{m} \mathrm{s}^{-1}$ to $3.5(7.0) \mathrm{km} \mathrm{s}^{-1}$ with the arithmetic means of $0.6(2.2) \mathrm{km} \mathrm{s}^{-1}$ (standard deviation $\sigma=1.6(3.6) \mathrm{km} \mathrm{s}^{-1}$ ) at the time of typhoon 18 and $1.5 \mathrm{~km} \mathrm{~s}^{-1}$ with $\sigma=3.2 \mathrm{~km} \mathrm{~s}^{-1}$ at the time of typhoon 19 .

(2) The corresponding wavelengths take the arithmetic means of $1.2 \times 10^{2}$ $\left(4.3 \times 10^{2}\right) \mathrm{km}$ with $\sigma=2.4 \times 10^{2}\left(6.9 \times 10^{2}\right) \mathrm{km}$ in the case of typhoon 18 , and $3.1 \times 10^{2} \mathrm{~km}$ 

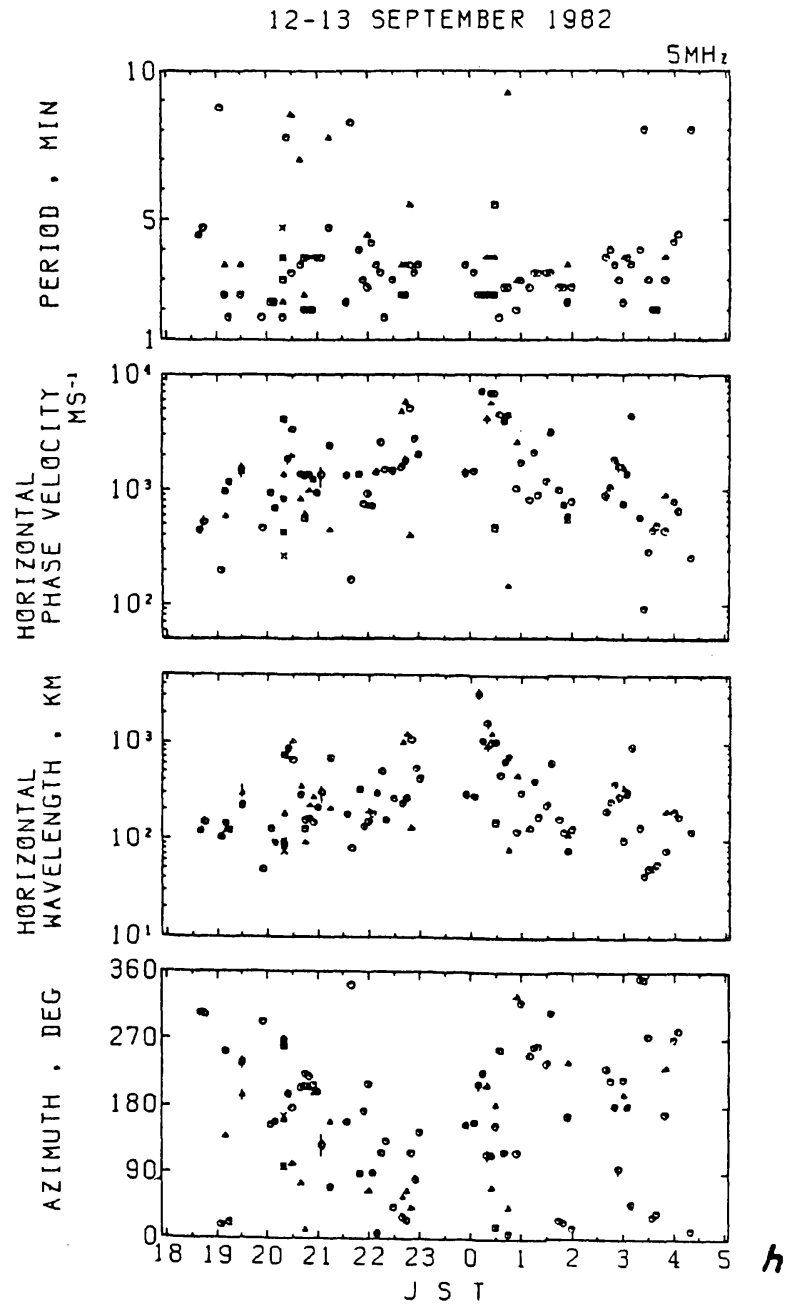

(b)

Fig. 7 (continued).

with $\sigma=5.2 \times 10^{2} \mathrm{~km}$ in the case of typhoon 19 .

(3) There are some remarkable changes of the azimuth in both the cases of typhoon 18 and 19. In the former, the azimuth took first the values around $150^{\circ}$ during the period from 7 to $10 \mathrm{~h}$, then it follows a quasi oscillatory pattern with the wave peaks around $11,12.5,14.5$ and $16 \mathrm{~h}$--in the daytime. No such changes are seen during the nighttime of the same typhoon, but the azimuth seems to favor the angles between $0^{\circ}$ and $180^{\circ}$ (i.e., the directions toward eastward hemisphere) during the period of 21 to $24 \mathrm{~h}$ (see Figs. 7(a) and (b)). In the case of typhoon 19, general trend of 

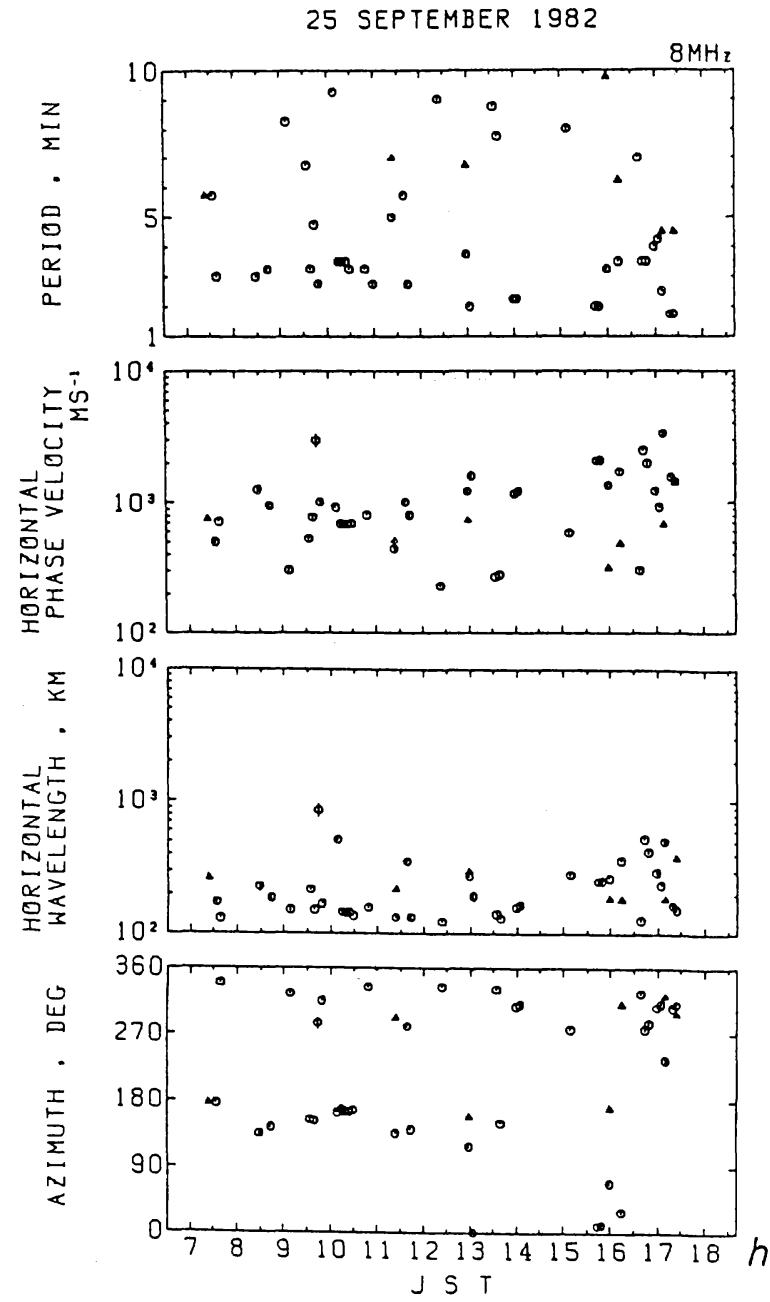

(c)

Fig. 7 (continued).

the propagation azimuths seems to be distributed around the directions of southeast (between $90^{\circ}$ and $180^{\circ}$ ) and northwest (between $270^{\circ}$ and $360^{\circ}$ ) (see Fig. 7(c)).

The two wave signals at 5 and $8 \mathrm{MHz}$ are useful for calculating the vertical phase velocity and wavelength. The Doppler data from Uji and Tokyo during the daylight hours of 12 and 25 September 1982, respectively, showing a clear sinusoidal feature, are used to make the cross-spectrum analyses. The spectral peak period, the corresponding upward vertical phase velocities and vertical wavelength are illustrated 


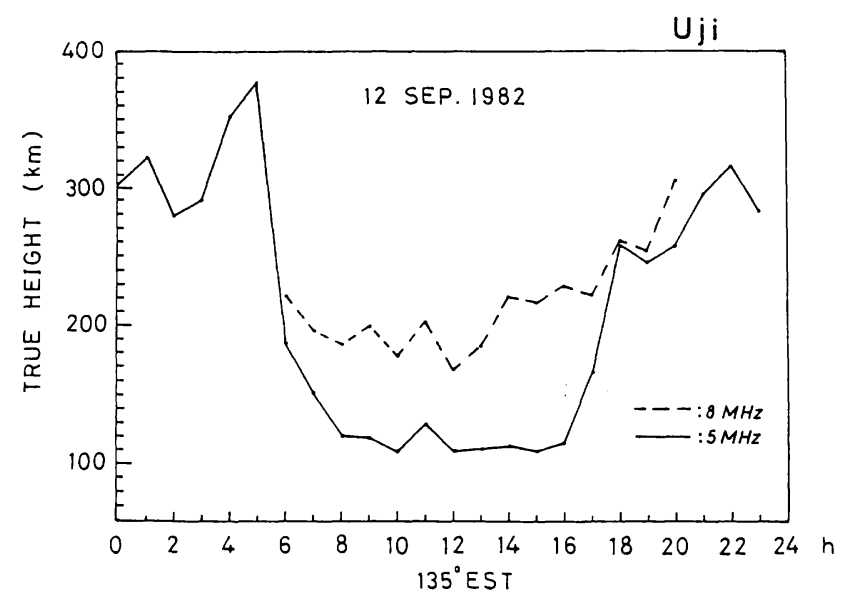

(a)

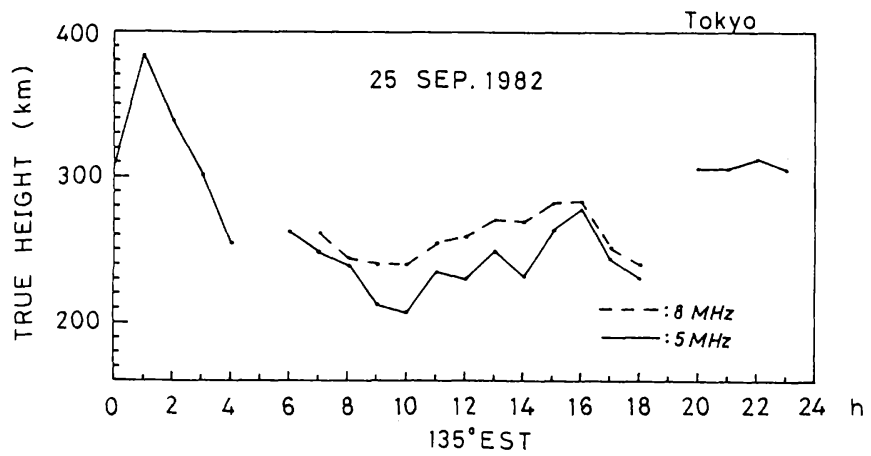

(b)

Fig. 8. True reflecting heights vs local time; (a) for Uji- Nazaki path on 12 September 1982, and (b) for Tokyo-Nazaki path on 25 September 1982.

from top to bottom in Fig. 9. The meaning of the spectral peak period is the same as that of Fig. 7, except that the autospectra are obtained from the two signals at different frequencies. Considering the properties of the wave normal surface of infrasound (HINES, 1960), only the upward propagation vectors are retained in this paper, although the downward ones in several tens percent of all are seen. It is found that (1) the vertical phase velocities take the arithmetic means of $6.4 \mathrm{~km} \mathrm{~s}^{-1}$ with standard deviation $\sigma=15.7 \mathrm{~km} \mathrm{~s}^{-1}$ in the case of typhoon 18 , and $3.7 \mathrm{~km} \mathrm{~s}^{-1}$ with $\sigma=12.9 \mathrm{~km} \mathrm{~s}^{-1}$ in the case of typhoon 19 , and (2) the vertical wavelengths take the arithmetic means of $8.9 \times 10^{2} \mathrm{~km}$ with $\sigma=2.01 \times 10^{3} \mathrm{~km}$ in the former case and $5.6 \times 10^{2} \mathrm{~km}$ with $\sigma=1.68 \times 10^{3} \mathrm{~km}$ in the latter case. These are several to ten times larger than those of the horizontal component. 

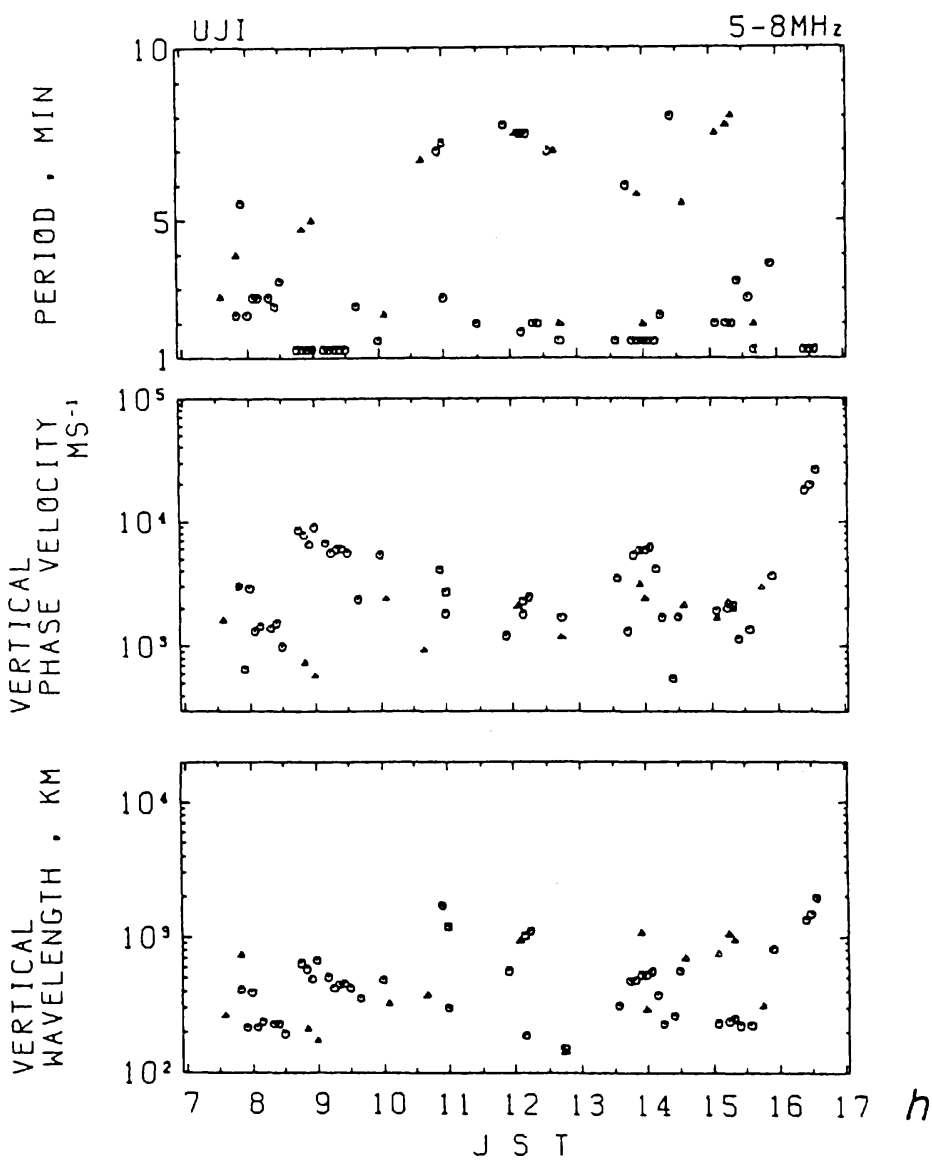

(a)

Fig. 9. (a) TID parameters (in the vertical direction) vs local time during the daylight hours of 12 September 1982 (typhoon 18). (b) The same as (a) but of 25 September 1982 (typhoon 19).

Since the standard deviation in each case is not so small as to convince us of the statistical significance of the results, it should be regarded as only a measure of data scatter.

\section{Discussion and Concluding Remarks}

Wavelike ionospheric fluctuations were observed by a network of HF Doppler receivers when typhoons 18 and 19 passed successively across the Islands of Japan in September 1982. The fluctuations were recorded during the period when the typhoon center was inside the circle with a radius of $450 \mathrm{~km}$ or so centered at the middle point 


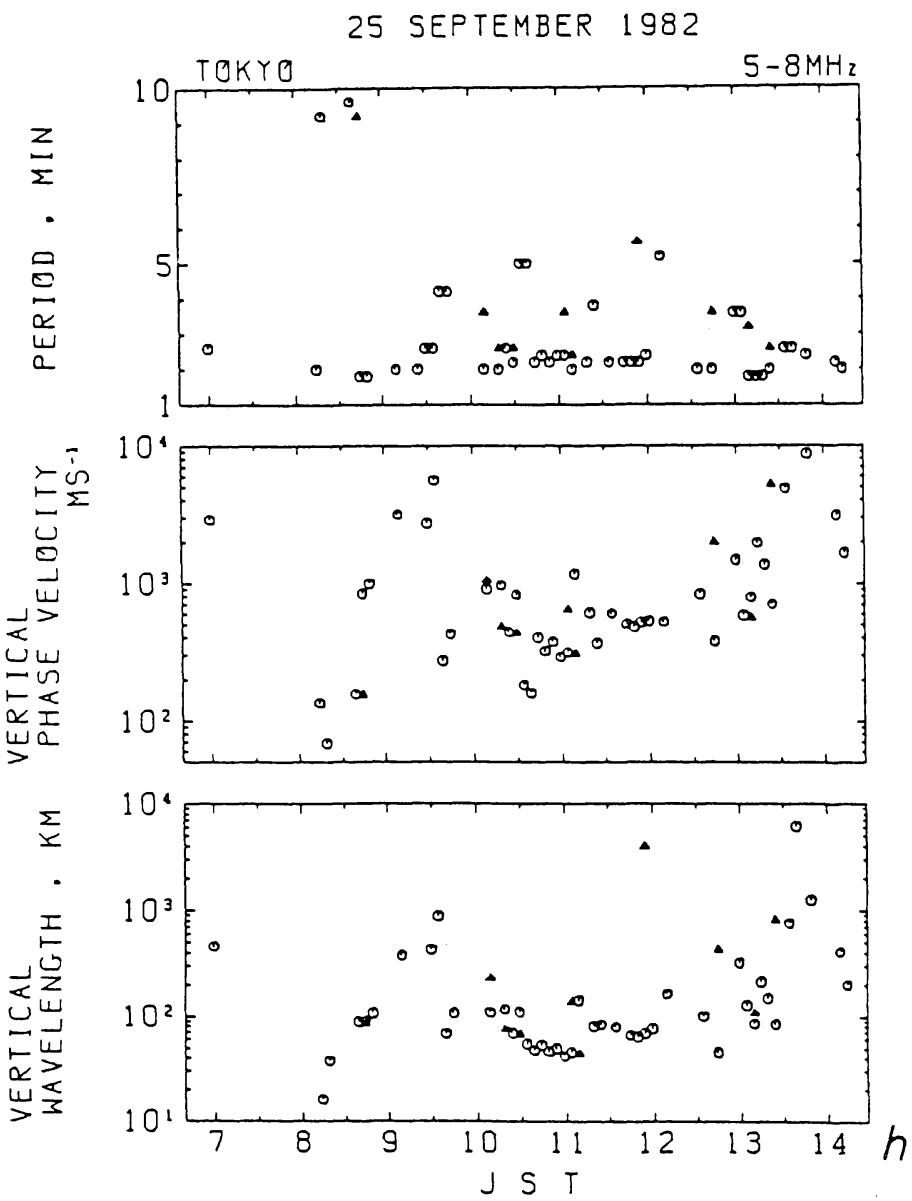

(b)

Fig. 9 (continued).

of the radio path, which is 1.5 times larger than that for the case of thunderstorm events so far reported (GEORGES, 1973). This will possibly be explained by the reason that the intensity of disturbance is slightly greater for a typhoon than that for a thunderstorm.

First, we made spectral analyses of the Doppler variations observed at each station to obtain dynamic as well as static power spectra using the maximum entropy technique. The results of the analyses have shown that (1) there are one, or several, sharply defined spectral peaks having the wave periods ranging from 1.4 to $9.7 \mathrm{~min}$, and (2) there are some kinds of variability in the spectral content, i.e., variabilities from hour to hour, from station to station even for a single typhoon, and one typhoon to the other. 
For heights greater than $110 \mathrm{~km}$, the acoustic cutoff period $\left(T_{\mathrm{a}}\right)$ and the Brunt period $\left(T_{\mathrm{B}}\right)$ are calculated using the mean atmosphere model of CIRA 1972 (COSPAR, 1972), assuming the gas constant $\gamma=1.4$ and an exospheric temperature of $1000 \mathrm{~K}$. The $T_{\mathrm{a}}\left(T_{\mathrm{B}}\right)$ takes the values of $4.6(5.1), 10.5(11.6), 13.1(14.5), 14.5(16.2) \mathrm{min}$ at the heights of $110,200,300$ and $400 \mathrm{~km}$, respectively. On the other hand, during the typhoon periods we are concerned with in this paper, the true reflecting heights of the radio wave for $8(5) \mathrm{MHz}$ signals are found in the range of $170(110)$ to $260(380) \mathrm{km}$ (for Uji-Nazaki path), and 240(210) to 285(280)km (for Tokyo-Nazaki path) (See Fig. 8). Comparison between these estimates makes us note that the daytime data of $5 \mathrm{MHz}$ wave signals from the Kansai subarray involve the gravity wave component at the wave periods of more than 5 min or so. Taking this note into account, we notice that the result described above in (1) except for the daytime data of $5 \mathrm{MHz}$ wave signals from the Kansai subarray will give evidence of the infrasonic waves generated by the typhoon crossing, and appears to support, so called, 'normal-mode theory' (e.g., JONES and GEORGES, 1976) that spectral fine structure is explained in terms of resonant interactions between the waves and the atmospheric temperature structure. However, an hour to hour variability of the spectra does not seem to accord with the normal-mode theory as well as the atmospheric filtering hypothesis (GEORGES, 1973). The reason is that the height distribution of temperature from the ground up to the thermosphere which plays a key role for determining the normal-mode frequencies will not change so much within an hour or less (COSPAR, 1972). It should be noticed also that the observed spectral fine structure in the present study does nor agree with the theoretical result by JONES and GEORGES (1976) (cf., Fig. 10 of their paper). It is likely, therefore, that the spectral fine structure is attributed to the infrasound sources in typhoon air mass itself.

Secondly, the TID parameters of several kinds vs local time have been estimated using the cross-correlation technique, or the multi-channel MEM.

Random nature of the distribution of the resultant spectral peaks along time axis may reflect characteristics of the radiation sources in typhoon air mass. Scatter range of the values of horizontal phase velocity for the present TID becomes $0.1-3.5 \mathrm{~km} \mathrm{~s}^{-1}$, and this is wider than that of the TIDs so far reported for severe thunderstorms $\left(0.8-1.0 \mathrm{~km} \mathrm{~s}^{-1}\right)$ and tornadoes $\left(0.6-0.7 \mathrm{~km} \mathrm{~s}^{-1}\right)$ (SMITH and HUNG, 1975). This suggests that there are turbulent eddies of many kinds of scale size which contribute to radiation sources in typhoon air mass in comparison with other convective storms.

Now, let the thermospheric neural wind be considered, which may affect the propagation characteristics of AGW generated by the typhoons. In the reflection heights of the radio waves, the neural wind takes maximum amplitude of less than 100 $\mathrm{m} \mathrm{s}^{-1}$ in the daytime and $300 \mathrm{~m} \mathrm{~s}^{-1}$ in the nighttime for the data period of this paper (CHO and YEH, 1970; SALAH and EVANS, 1977). The direction of the wind changes from westward ( $09 \mathrm{~h} \mathrm{LT})$ to eastward (18 h LT) via northward in the daytime, and then to southwestward $(04 \mathrm{~h} \mathrm{LT})$ via southward in the nighttime. Taking the horizontal wavelengths of $200 \mathrm{~km}$ for daytime and $400 \mathrm{~km}$ for nighttime and the neutral winds of $100 \mathrm{~m} \mathrm{~s}^{-1}$ and $300 \mathrm{~m} \mathrm{~s}^{-1}$, respectively, into account, the effective contribution to the frequency of acoustic wave (with the period of $3 \mathrm{~min}$ ) is about 
one-tenth in both cases of day and night, compared with that in the absence of the wind. Therefore, in our case, the influence of neutral wind on the spectra can be practically neglected.

Next, combining the daytime horizontal wavelengths (Fig. 7(a) and (c)) with the vertical ones (Fig. 9), we can approximately calculate the elevation angles of the TID propagation vector. Median values of the elevation angles thus obtained are $82^{\circ}$ in the case of typhoon 18 (12 Sept. 1982) and 61 ${ }^{\circ}$ in the case of typhoon 19 (25 Sept. 1982). Using average values for the January and July models of the 1966 U.S. Standard Atmosphere for heights less than $25 \mathrm{~km}$ and the mean CIRA 1972 model (COSPAR, 1972) for heights greater than $25 \mathrm{~km}$, we have calculated the sound speed and the ray path for infrasonic waves that start from $10 \mathrm{~km}$ height above the ground for 2, 3 and 4 min wave periods, respectively. The calculations indicate that the launch angles to the vertical direction which correspond to the $82^{\circ}$ and $61^{\circ}$ elevation angles of the ionospheric propagation vectors, if the mean sounding heights are taken to be $130 \mathrm{~km}$ and $260 \mathrm{~km}$, respectively, are found around $7^{\circ}$ (in the case of typhoon 18) and in the range from $12^{\circ}$ to $19^{\circ}$ (in the case of typhoon 19), respectively. The calculated results show that the corresponding horizontal distances between the launching point of the infrasonic waves at $10 \mathrm{~km}$ level and the reflection points of the 5 and $8 \mathrm{MHz}$ radio waves are in the range from 7 to $11 \mathrm{~km}$ and from 73 to $88 \mathrm{~km}$, respectively. Circles with radii of the latter distances centered at the mid-path points between the JJY station and the stations of the Kanto subarray do not overlap the storm zone (250-300 $\mathrm{km}$ in diameter) of typhoon 19, but those associated with the former distances and the stations of the Kansai subarray surely overlap the storm zone (250 $\mathrm{km}$ in diameter) of typhoon 18, during the daylight hours of 25 and 12 September 1982, respectively. It seems, then, open to question as to whether we could unambiguously measure the TID parameters using the Kanto subarray; this will be touched upon again later.

Since the ionospheric acoustic waves of tropospheric origin must have the propagation vector in an upward direction (HINES, 1960), several cases of downward vectors obtained from our analyses (even at the wave periods shorter than $5 \mathrm{~min}$ in the case of typhoon 18) may be due to sources other than typhoon, e.g., supersonic auroral arc motion (SWIFT, 1973), otherwise, a secondary wave produced through nonlinear interaction of the acoustic waves originating from either the typhoon or other sources (JURÈN and STENFLO, 1973). In this connection, it is to be noticed that shear flow instabilities in the tropopause jet may be a source of acoustic gravity waves (BERTIN et al., 1978). Satellite measurements (POTTER et al., 1976) have shown a secondary maxima of occurrence of the acoustic gravity wave at middle latitude, although no scale sizes were reported. The sporadic-E blanketing of the F-layer (FROM, 1983) may contaminate the HF Doppler data to a certain degree. A detailed investigation of these problems will be left for our future study.

The time variations in the horizontal directions of TID at the time of typhoon 18, of which characteristics have been summarized in the previous section, may follow to some extent the storm activity of that typhoon. For example, it is registered on the weather map from Japan Meteorological Agency that the wind at ground level near 
the mid-path points of radio wave for the Kansai subarray was directed southward at $9 \mathrm{~h}$ and eastward at $21 \mathrm{~h} 12 \mathrm{~d}$ JST. These seem consistent with the morning and midnight features, respectively, of the observed azimuths of TID. Quasi oscillatory time variation in azimuth seen from Fig. 7(a) may follow the apparent source direction that often shifts abruptly in response to the death of one emitter and the birth of another nearby, since the typhoon 18 was rapidly approaching the middle points of radio path at that time.

Another regularity that the majority of the calculated azimuthal angles distribute around the southeastward or the northwestward directions in the case of typhoon 19 (Fig. 7(c)) may reflect some uncertainty for the determination of azimuth, because the horizontal separations of the sounding points of the Kanto subarray amount to $63-134 \mathrm{~km}$ which are beyond the utmost distance $(50 \mathrm{~km})$ that unambiguous azimuth determination was possible in the case of infrasound from convective storms in the continental USA (GEORGES, 1973).

The HF Doppler fluctuations associated with the thunderstorms has already been interpreted in terms of infrasonic waves originating in the turbulent air mass and traveling upward by BAKER and DAVIES (1969), DAVIES and JONES (1972) and GEORGES (1973). They reported that the quasi sinusoidal fluctuations were observed when severe thunderstorms with cloud tops in excess of $12 \mathrm{~km}$ or so occur within a radius of $300 \mathrm{~km}$ or more from the radio reflection points or only when intense updrafts penetrated the tropopause. In fact, SHENK (1974) observed up-down motions of the top height of cloud domes above the cirrostratus anvil for several storm events over Texas using photographs taken from a Lear Jet and ground-based radar measurements. Based on the theoretical prediction by LIGHTHILL (1952, 1954, 1962) and STEIN (1967), it will reasonably be assumed that the infrasonic motions of the cloud tops, or the overshooting and collapsing convective turrets, are closely related to the observed ionospheric infrasound.

Observation of the hurricane eye wall by radar echoes made by MALKUS (1960) indicated that the wall cloud penetrates well above the tropopause. This may be true also in the typhoon case. HUNG and SMITH (1979) calculated possible wave periods of the cloud top motions using the data reported by SHENK (1974), and have shown the resultant values fall on the category of the acoustic waves.

A comparison between our data during typhoons and those during thunderstorms observed so far in the USA and India makes us infer that the dynamical oscillations generated by the air mass may not be universal and may be dependent upon the meteorological details of the formation of the turbulent-cloud cell. This study, thus, suggests that the measurement of ionospheric short-period waves associated with typhoons, together with the study of the growth and collapse of convective shooting turrets based on vehicle photographs, will contribute to the understanding of the dynamical behavior of typhoons as well as the role of $\mathrm{AGW}$ in the thermospheric dynamics.

The authors wish to acknowledge the Ministry of Education, Science and Culture of Japan for their financial support of our present study as one of the MAP projects. Thanks are 
extended to M. Shitamiti, Japan Meteorological Agency, for supplying typhoon data, and I. Tomizawa, Sugadaira Space Radio Wave Observatory of UEC, for help in pursuing the array observation. The authors thank also the referees whose comments are valuable for improving the original version of this paper. The ionograms used in this study were provided from the World Data Center C-2 for Ionosphere. The numerical calculations were performed mainly using the facility of the Information Processing Center, University of Electro-Communications.

\section{REFERENCES}

Akaike, H. and T. Nakagawa, Statistical Analysis and Control of Dynamic Systems, 50pp., Science Company, Tokyo, 1972 (in Japanese).

Aкima, H., A new method of interpolation and smooth curve fitting based on local procedures, J. Assoc. Comput. Machin., 17, 589-602, 1970.

BAKer, D. M. and K. DAvies, $F_{2}$-region acoustic waves from severe weather, J. Atmos. Terr. Phys., 31, 1345-1352, 1969.

BEHANNon, K. W. and N. F. NESs, The design of numerical filters for geomagnetic data analysis, NASA Tech. Rept., TND-3341, 1966.

Bertin, F., J. Testud, L. Kersley, and P. R. Rees, The meteorological jet stream as a source of medium scale gravity waves in the thermosphere: an experimental study, J. Atmos. Terr. Phys., 40, 1161-1183, 1978.

BOOKER, H. G., The role of acoustic gravity waves in the generation of spread-F and ionospheric scintillation, J. Atmos. Terr. Phys., 41, 501-515, 1979.

Burg, J. P., Maximum entropy spectral analysis, Ph.D. Thesis, Stanford Univ., Calif., 1975.

Chen, C. H., Nonlinear Maximum Entropy Spectral Analysis Methods for Signal Recognition, 45pp., Research Studies Press, Chichester, 1982.

CHO, H. R. and K. C. YEH, Neutral winds and the behavior of the ionospheric $F_{2}$ region, Radio Sci., 5 , 881-894, 1970.

COSPAR, COSPAR International Reference Atmosphere 1972, Akademie, Berlin, 1972.

Coutillot, V., J. L. Le Mouël, and P. N. Mayaud, Maximum entropy spectral analysis of the geomagnetic activity index aa over a 107-year interval, J. Geophys. Res., 82, 2641-2649, 1977.

Davies, K., Ionospheric Radio Waves, 233pp., Blaisdell Pub., Waltham, Mass., 1969.

DAvies, K. and J. E. Jones, Ionospheric disturbances in the F2 region associated with severe thunderstorms, J. Atmos. Sci., 28, 254-262, 1971a.

DAVIES, K. and J. E. JoNES, Three-dimensional observations of travelling ionospheric disturbances, $J$. Atmos. Terr. Phys., 33, 39-46, 1971 b.

DAviEs, K. and J. E. Jones, Infrasound in the ionosphere generated by severe thunderstorms, J. Acoust. Soc. Am., 52, 1087-1090, 1972.

DAviES, K. and J. E. JonES, Acoustic waves in the ionospheric $F_{2}$-region produced by severe thunderstorms, J. Atmos. Terr. Phys., 35, 1737-1744, 1973.

FROM, W. R., Sporadic E movement followed with a pencil beam high frequency radar, Planet. Space Sci., 31, 1397-1407, 1983.

GEORGES, T. M., Evidence for the influence of atmospheric waves on ionospheric motions, J. Geophys. Res., 72, 422-425, 1967.

Georges, T. M., HF Doppler studies of traveling ionospheric disturbances, J. Atmos. Terr. Phys., 30, 735-746, 1968.

GEORGES, T. M., Infrasound from convective storms: examining the evidence, Rev. Geophys. Space Phys., 11, 571-594, 1973.

Hines, C. O., Internal atmospheric gravity waves at ionospheric heights, Can. J. Phys., 38, 1441-1481, 1960.

HuAng, Y.-N., K. Cheng, and S.-W. Chen, On the detection of acoustic-gravity waves generated by typhoon by use of real time HF Doppler frequency shift sounding system, Radio Sci., 20, 897-906, 1985 . 
Hung, R. J. and J. P. Kuo, Ionospheric observation of gravity waves associated with Hurricane Eloise, $J$. Geophysics, 45, 67-80, 1978.

Hung, R. J. and R. E. SMITH, Dynamics of severe storms through the study of thermospheric-tropospheric coupling, J. Geomag. Geoelectr., 31, 183-194, 1979.

JONES, R. M. and T. M. GEORGES, Infrasound from convective storms. III propagation to the ionosphere, J. Acoust. Soc. Am., 59, 765-779, 1976.

JurÈn, C. and L. Stenflo, On resonant interaction of atmospheric waves, Radio Sci., 8, 651- 652, 1973.

Kelly, M. C., M. F. LARSEN, C. LAHoz, and J. P. MCCluRE, Gravity wave initiation of equatorial spread F: a case study, J. Geophys. Res., 86, 9087-9100, 1981.

Klostermeyer, J., Thermospheric heating by atmospheric gravity waves, J. Atmos. Terr. Phys., 35, 2267-2275, 1973.

Lighthill, M. J., On sound generated aerodynamically: I. general theory, Proc. R. Soc., A221, 564-587, 1952.

LighthiLl, M. J., On sound generated aerodynamically: II. turbulence as a source of sound, Proc. R. Soc., A222, 1-32, 1954.

Lighthill, M. J., Sound generated aerodynamically, Proc. R. Soc., A267, 147-182, 1962.

MalKuS, J. S., Recent development in studies of penetrative convection and the application to hurricane cumulo-nimbus towers, in Cumulus Dynamics, pp.65-84, Pergamon Press, New York, 1960.

Okuzawa, T. and K. Davies, Pulsations in total columnar electron content, J. Geophys. Res., 86, 1355-1363, 1981.

Potter, W. E., D. C. Kayser, and K. Mauersberger, Direct measurements of neutral wave characteristics in the thermosphere, J. Geophys. Res., 81, 5002-5012, 1976.

Prasad, S. S., L. J. Schneck, and K. Davies, Ionospheric disturbances by severe tropospheric weather storms, J. Atmos. Terr. Phys., 37, 1357-1363, 1975.

Raju, D. G. K., M. S. Rao, B. M. Rao, C. Jogulu, C. P. Rao, and R. Ramanadham, Infrasonic oscillations in the $F_{2}$ region associated with severe thunderstorms, J. Geophys. Res., 86, 5873-5880, 1981.

Roble, R. G. and R. E. Dickinson, Is there enough solar extreme ultraviolet radiation to maintain the global mean thermospheric temperature?, J. Geophys. Res., 78, 249- 257, 1973.

RÖTTGER, J., Equatorial spread-F by electric fields and atmospheric gravity waves generated by thunderstorms, J. Atmos. Terr. Phys., 43, 453-462, 1981.

Salah, J. E. and J. V. Evans, Tests of electrodynamic consistency from daytime ionospheric drift observations, J. Geophys. Res., 82, 2413-2418, 1977.

Shenk, W. E., Cloud top height variability of strong convective cells, J. Appl. Meteorol., 13, 917-922, 1974.

Shibata, T. and T. OKuZawa, Horizontal velocity dispersion of medium-scale travelling ionospheric disturbances in the F-region, J. Atmos. Terr. Phys., 45, 149-159, 1983.

SMITH, R. E. and R. J. Hung, Observation of severe weather activities by Doppler sounder array, J. Appl. Meteorol., 14, 1611-1615, 1975.

Stein, R. F., Generation of acoustic and gravity waves by turbulence in an isothermal stratified atmosphere, Solar Phys., 2, 385-432, 1967.

STRAND, O. N., Multichannel complex maximum entropy (auto-regressive) spectral analysis, IEEE Trans. on Automatic Control, AC-22, 634-640, 1977.

SwIFT, D. W., The generation of infrasonic waves by auroral electrojet, J. Geophys. Res., 78, 8205-8221, 1973.

Titheridge, J. E., The overlapping polynomial analysis of ionograms, Radio Sci., 2, 1165-1169, 1967.

Tsutsui, M. and T. OGawa, HF Doppler observation of ionospheric effects due to typhoons, Rept. Ionos. Space Res. Japan, 27, 121-123, 1973. 